\title{
Cocaine- and amphetamine-regulated transcript promotes the differentiation of mouse bone marrow-derived mesenchymal stem cells into neural cells
}

Zhuo Liu' ${ }^{1,2,4,5}$, Danqing Huang ${ }^{3}$, Meijuan Zhang ${ }^{2,4}$, Zhibin Chen ${ }^{2,4,5}$, Jiali Jin ${ }^{2,4}$, Siyuan Huang ${ }^{2,4}$, Zhuo Zhang ${ }^{2,4,5}$, Zhongyuan Wang ${ }^{2,4,5}$, Lei Chen ${ }^{6}$, Ling Chen ${ }^{6}$ and Yun $\mathrm{Xu}^{1,2,4,5^{*}}$

\begin{abstract}
Background: Neural tissue has limited potential to self-renew after neurological damage. Cell therapy using BMMSCs (bone marrow mesenchymal stromal cells) seems like a promising approach for the treatment of neurological diseases. However, the neural differentiation of stem cells influenced by massive factors and interactions is not well studied at present.

Results: In this work, we isolated and identified MSCs from mouse bone marrow. Co-cultured with CART (0.4 nM) for six days, BM-MSCs were differentiated into neuron-like cells by the observation of optical microscopy. Immunofluorescence demonstrated that the differentiated BM-MSCs expressed neural specific markers including MAP-2, Nestin, NeuN and GFAP. In addition, NeuN positive cells could co-localize with TH or ChAT by doublelabled immunofluorescence and Nissl bodies were found in several differentiated cells by Nissl stain. Furthermore, BDNF and NGF were increased by CART using RT-PCR.

Conclusion: This study demonstrated that CART could promote the differentiation of BM-MSCs into neural cells through increasing neurofactors, including BNDF and NGF. Combined application of CART and BM-MSCs may be a promising cell-based therapy for neurological diseases.
\end{abstract}

\section{Background}

Mesenchymal stem cells (MSCs) are attractive for the regeneration of damaged tissues in clinical applications, since they are characterized as undifferentiated cells, able to self-renew with a high proliferative capacity and possess mesodermal differentiation potential [1]. Bone marrow-derived MSCs have great potential as therapeutic agents for neurological diseases, because they are easily obtained from bone marrow and expand rapidly in vitro. Moreover, there is a lower risk of rejection using MSCs compared to other sources of stem cells as they can be autogenic. It has been held that MSCs can give rise to osteocytes, chondrocytes, adipocytes, and neural cells $[2,3]$. However, current induction methods

\footnotetext{
*Correspondence: xuyun20042001@yahoo.com.cn

'Department of Neurology, Drum Tower Hospital of Nanjing Medical

University, 321 Zhongshan Road, Nanjing, Jiangsu, 210008, PR. China

Full list of author information is available at the end of the article
}

obtain a lower percentage of neural differentiation and consume long induction time.

Cocaine- and amphetamine-regulated transcript (CART) peptides have emerged as major neurotransmitters and hormones. They are widely distributed in the CNS and involved in regulating many processes, including food intake, the maintenance of body weight and endocrine functions. Moreover, previous study demonstrated that CART was up-regulated in the cerebral cortex following focal cerebral ischemia in vivo and in cultured cortical neurons subjected to oxygen-glucose deprivation (OGD) in vitro. This regulation led to the reduction of infarct size and OGD-induced cell death [4]. Also, CART promoted the survival and differentiation of primary hippocampal neurons by up-regulating BDNF mRNA expression and protein synthesis [2].

NGF is critical for the survival and maintenance of sympathetic and sensory neurons. Without it, these 
neurons undergo apoptosis [3]. Nerve growth factor induces axonal growth including axonal branching and a bit of elongation [5]. BDNF is the second neurotrophic factor to be characterized after NGF. They help support the survival of existing neurons and encourage the growth and differentiation of new neurons and synapses $[6,7]$. Emerging evidence established that growth factors such as BDNF and NGF are physiological inductors for neural differentiation of MSCs not only in the MSCs, recipients but also in the MSCs, co-cultured medium $[8,9]$.

This study tested the hypothesis that CART could promote the differentiation of MSCs into neural cells through increasing neurofactors such as BNDF and NGF.

\section{Results}

1. Identification of mouse MSCs

Firstly, cell morphology was observed daily by phase contrast invert microscopy. In the early days, individual adherent cells appeared. Among the adherent cells, some were fibroblastic in shape and the others were round with dark centers and transparent peripheries. In the subsequent days, some fibroblastic cells proliferated. They gave rise to clones of pure fibroblastic cells, each of which was composed of several cells. Finally, these cells were almost completely obscured by the fibroblastic cells (Figure 1B). Fluorescent activated cell sorting (FACS) analysis demonstrated that the expanded plastic adherent cells were positive for the mesenchymal stem cell-associated surface markers CD29, CD44 and CD99, but negative for the hematopoietic progenitor's specific surface maker CD34 (Figure 1A). Thus, the cells used in this study fulfilled all criterion to be defined as MSCs.

\section{Neuronal induction of mouse MSCs treated by CART 2.1 Cell Culture}

48-72 h after induction, some cells became shorter. In addition, the cytoplasm gathered towards the nucleus and formed the axons and dendrites (Figure 2). Another 3 days later, the majority of cells turned into neuronlike cells. They had large and round cell bodies with longer axons similar to the shape of cells induced by endothelial growth factor (EGF) and basic fibroblast grow factor (bFGF). The uninduced group remained in fiber-like cells (Figure 2).

\subsection{Immunofluorescence Assay of neural marker proteins}

MSCs treated or not treated by CART were prepared for immunofluorescence analysis by antibodies against the neural precursor Nestin (green, Figure 3A), the markers of neurons MAP-2 (red, Figure 3C) and NeuN (green, Figure 3B), and the marker of astrocytes GFAP (green, Figure 3D). Quantification of immunofluorescence staining from three independent experiments revealed that Nestin, MAP-2, GFAP and NeuN were $25.4 \pm 2.1 \%, 30.8 \pm 4.7 \%, 20.5 \pm 2.5 \%, 32.1 \pm 2.3 \%$ of all cells in 3 days and $47.1 \pm 1.9 \%, 41.2 \pm 3.1 \%, 21.3 \pm$ $2.2 \%, 40.3 \pm 2.7 \%$ in 6 days (Table 1 ), respectively. A similar rate of conversion was induced by EGF/bFGF, with $27.1 \pm 2.0 \%, 29.3 \pm 3.7 \%, 11.4 \pm 2.6 \%, 31.1 \pm 2.9 \%$ in 3 days and $37.1 \pm 2.9 \%, 33.2 \pm 3.0 \%, 14.8 \pm 4.2 \%$, $39.3 \pm 3.8 \%$ in 6 days. Only a trace amount of MSCs in the untreated group expressed low levels of Nestin (8.2 $\pm 2.2 \%$ in 3 days, $13.1 \pm 3.0 \%$ in 6 days) but no MAP-2, GFAP or NeuN.

\subsection{Function of these differentiated cells}

To investigate the function of differentiated neurons, ChAT (specific surface expression in cholinergic neurons) and TH (marker of dopaminergic neurons) were detected by immunofluorescence. Results showed that a few NeuN positive cells co-expressed ChAT (Figure 4A) or TH (Figure 4B). The MSCs in the control and the growth factor-treated groups hardly expressed either of them. Also, we carried out the Nissl stain to look for Nissl bodies among the MSCs with CART for 6 days. We found that Nissl bodies existed as dark blue particles in the cytoplasm of several differentiated MSCs (Figure 4C). No similar structure was detected in control group. What is more, excitable properties of MSCderived neural like cells were detected by whole cell recording. Voltage-gated potassium current and voltagegated calcium current were elicited in CART treated MSCs (Additional file 1).

\section{CART up-regulated neurofactors BDNF and NGF}

In addition to immunofluorescence assay, the neural specific RNA transcripts BDNF and NGF were amplified by RT-PCR. For each marker, the RNA extracts of MSCs were used as controls. This study showed that BDNF and NGF were highly induced on 6 days after CART treatment. Compared to the control group, the amount of BDNF was 1.68 folds ( $p>0.05$ ) and 2.45 folds $(\mathrm{p}<0.05)$ higher with the incubation of CART 3 days and 6 days. NGF was also higher with the incubation of CART, with 1.05 fold of control group in Day 3 $(\mathrm{p}>0.05)$ and 2.01 folds of control group in Day 6 (p < 0.05 ). There were no significant differences between CART treated-group and growth factor treated-group (Figure 5).

\section{Discussion}

In the present study, we thoroughly assessed for the first time the capacity of CART to enhance the neural differentiation of MSCs. We demonstrated that, when exposed to CART, MAP-2, GFAP or NeuN positive cells were traced in the cultured MSCs. Furthermore, the proposed differentiated neurons not only have the potency to express ChAT and $\mathrm{TH}$, but also display the 

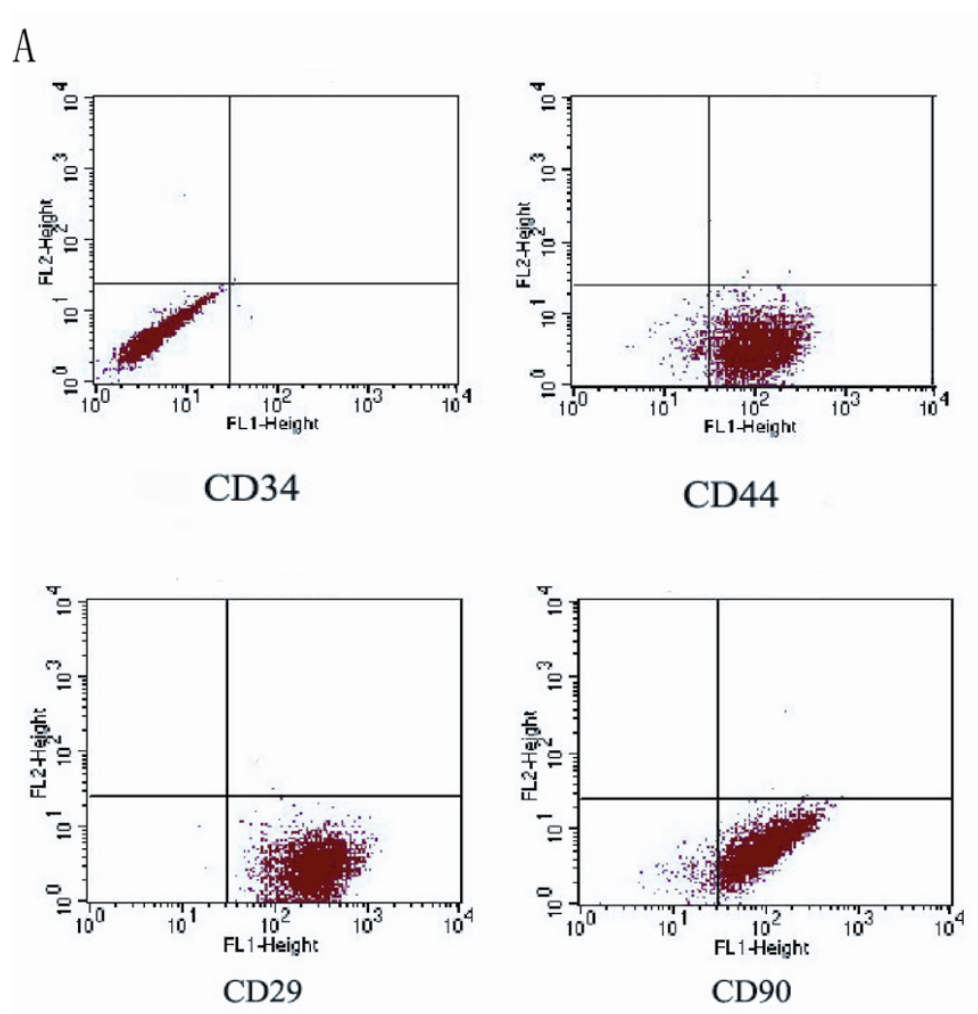

B

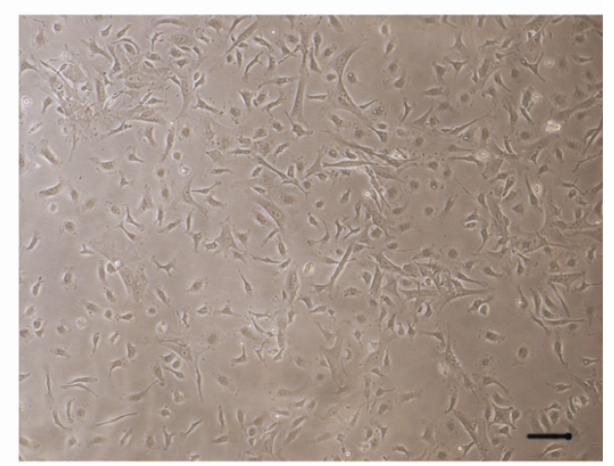

Figure 1 Identification of MSCs in vitro. Identification of BM-MSC in vitro. (A) The fluorescent activated cell sorting analysis showed that the adherent cells were positive for the well-defined MSC surface markers including CD29, CD44, and CD99, while negative for CD34. CD34 precluded the origination of hematopoietic progenitors. (B) MSCs extracted from the mouse bone marrow presented the fibroblastic shape with dark centers as well as transparent peripheries by the observation of phase contract invert microscopy (scale bar $=50$ uM).

Nissl bodies in the cytoplasm. In addition, neurotrophic factors including NGF and BDNF were up-regulated in CART-treated group. Our results suggest that CART may promote the differentiation of MSCs in vitro by enhancing the endogenous expression of NGF and BDNF.

MSCs extracted from mouse bone marrow have great multiplication potency. Cell-doubling time is $48-72 \mathrm{~h}$ and cells can be expanded in culture for more than 60 doublings [10]. Herein, we isolated BM-MSCs with the characteristics involving adherence to cell culture plastic, specific surface antigen expression, and multipotent differentiation which met the criterion defined by the Mesenchymal and Tissue Stem Cell Committee of the International Society for Cellular Therapy [11]. Also, BM-MSCs possess pluripotency defined by their ability to differentiate into bone, fat, cartilage and muscle [1,12-14]. Compelling evidences unveiled that MSCs are competent to break germ layer commitment and differentiate into cells expressing neuroectodermal properties [15]. Such a capacity opens extensive possibilities for autologous therapeutic treatments in a variety of neurological disorders. Also, as there are ethical issues related to isolating stem cells from fetal tissue and from adults, alternative sources of neuron-like cells for cell therapy are necessary. Indeed, a portion of studies indicate that, in contrast to the primary stem cells, the transplantation of pre-differentiated stem cells can diminish the risk of tumogenesis in the host patients [16]. However, current inducing methods obtain a lower percentage of neuronal differentiation by a long inducing time [17]. In 2000, Sanchez-Ramos et al used RA in combination with BDNF to introduce differentiation of BMSC to neural phenotypes. NeuN and GFAP positive cells only rank 0.5 and $1 \%$ respectively [18]. Likewise, Woodbury et al found $\beta$-mercaptoethanol (BME) can rapidly induce the transition from MSCs into neurons but not glial cells [19]. There is also a debate about whether or not the converted neural phenotyped cells are able to work [20]. This premise provided the impetus to investigate better and new reagent which can yield functional neuronal cells at a high rate.

Here we extended our study on the neuroectodermal conversion of BM-MSCs in vitro by exposure to the prospective peptide CART. After treatment with CART, we found that CART could successfully differentiate MSCs into neural cells in vitro. These cells were 


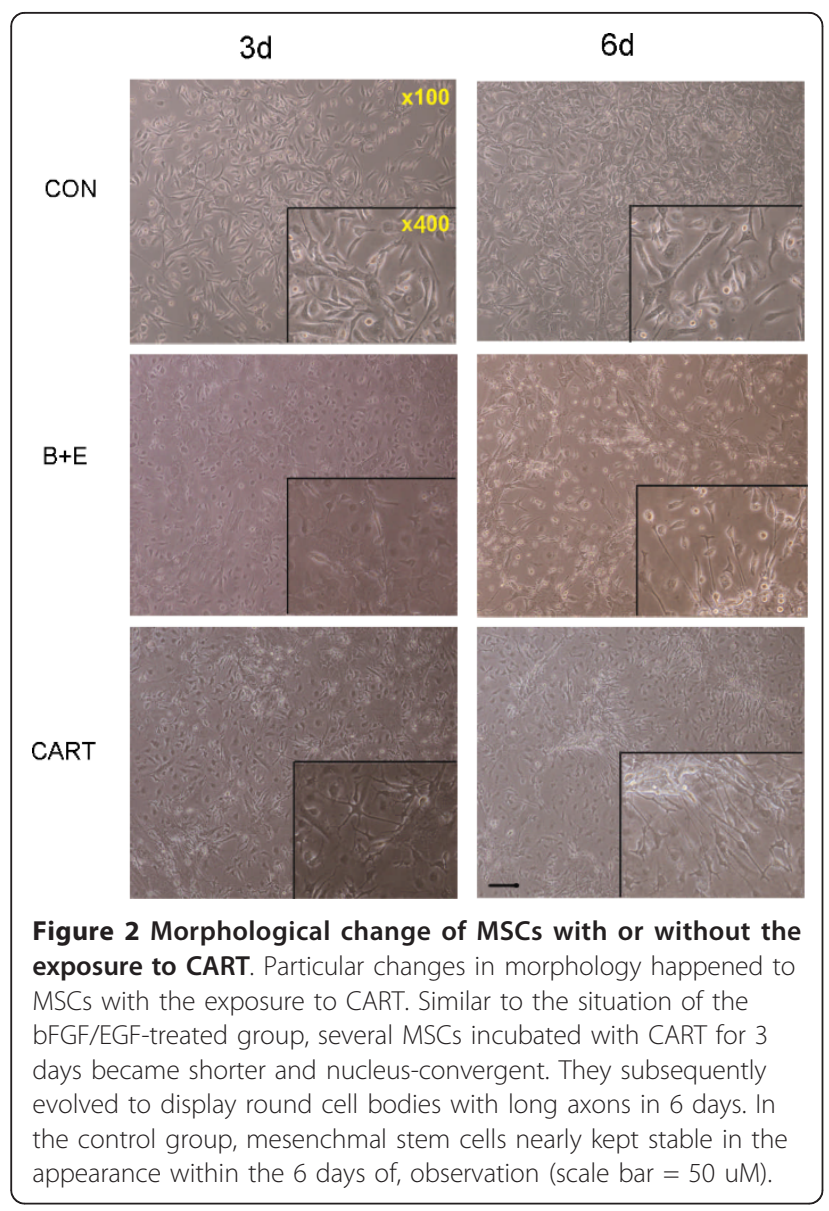

morphologically similar to neural stem cells. More importantly, they could express neural progenitor stem cell marker Nestin and mature glial marker GFAP as well as mature neuron markers like MAP-2 and NeuN. It indicated that the protocol of using CART for three or six days induced significant changes in morphology and expression of markers of early and mature neural cell types. Similar with induction rate of bFGF plus EGF, CART exposure obtained that MAP-2, GFAP and NeuN expressions were found in $30.8 \pm 4.7 \%, 20.5 \pm$ $2.5 \%, 32.1 \pm 2.3 \%$ of all cells in 3 days, and $41.2 \pm 3.1 \%$, $21.3 \pm 2.2 \%, 40.3 \pm 2.7 \%$ in 6 days (Figure 4). However, the expression of one or even two neuronal proteins does not prove that the cell bearing these "neuronal markers" is capable of all the complex functions of a neuron. It will be important to determine whether these cells possess functional characteristics of neurons. Subsequently, double-labeled immunofluorescence was performed to calculate the function of the converted cells. It was intriguing that the differentiated NeuN positive cells co-expressed ChAT or TH. Our study on excitable property of MSC-derived neural like cells demonstrated that the differentiated cells pocess founctional patassium and cacium channels (Additional file 1). Recent research discovered that the neuron-like cells differentiated from BM-MSCs resemble the endogenous neural progenitors in morphological, immunocytochemical, and functional characteristics [21]. Another independent investigator also reported that the transformed BM-MSCs exhibit both neuron-like biochemical function and some corresponding electrophysiological properties [22].

CART is an endogenous neuropeptide which is widely distributed in the brain and peripheral nervous system. It has been well-established that CART can promote the survival and differentiation of neurons. Some investigators disclosed that CART has the capability to modulate the expression of growth factors and neurotrophic factors, which probably participated in the underlying effect of CART [23]. Based on this theory, we made an assumption that neurotrophic factors could be the bridge between CART and stem cell differentiation. In order to verify this hypothesis, the amount of NGF and BDNF was determined by RT-PCR. The result that neurotrophic factors are significant higher in CART treated group implied CART could promote the endogenous production of neurotrophic factors. Neurotrophic factors in cell and tissue culture have been shown to promote neuronal survival and differentiation and also regulate the growth of axons and dendrites [24,25]. The presence of growth factors such as BDNF or NGF in the transplantation or the co-culture experiment are considered as physiological inductors for neural differentiation of MSCs $[8,9]$. MSCs can induce a variety of neuro-regulatory proteins in addition to BDNF and $\beta$-NGF [26]. Further study demonstrated that the NGF and BDNF receptor TrkA and TrkB do exist on the surface of MSCs [27]. Moreover, the TrkB receptor modified by BDNF may trigger the MAPK signal pathway. This process contributes to the maturation and neural differentiation of MSCs [20]. Early studies confirmed that BDNF+RA (retinoic acid) adult bone marrow stromal cells can be induced to differentiate into neural cells in vitro [28]. However, CART stimulated the endogenous BDNF and NGF expression of MSCs. This stimulation may imitate the natural physiological pattern. As a result, we obtained a higher yield rate than in previous studies. In the hippocampus, BDNF and other neurotrophins are expressed from early stage of neuron development $[29,30]$. This process is a prerequisite for the differentiation of neurons derived from hippocampal precursor cells in vitro [31-33]. Overall, findings suggest that the BDNF and NGF enhanced by CART may be the foundation of stem cell differentiation and maturation.

\section{Conclusion}

In summary, we identified CART as a potential neurotrophic factor. CART can promote the neural differentiation of BM-MSCs, probably through enhancing the 


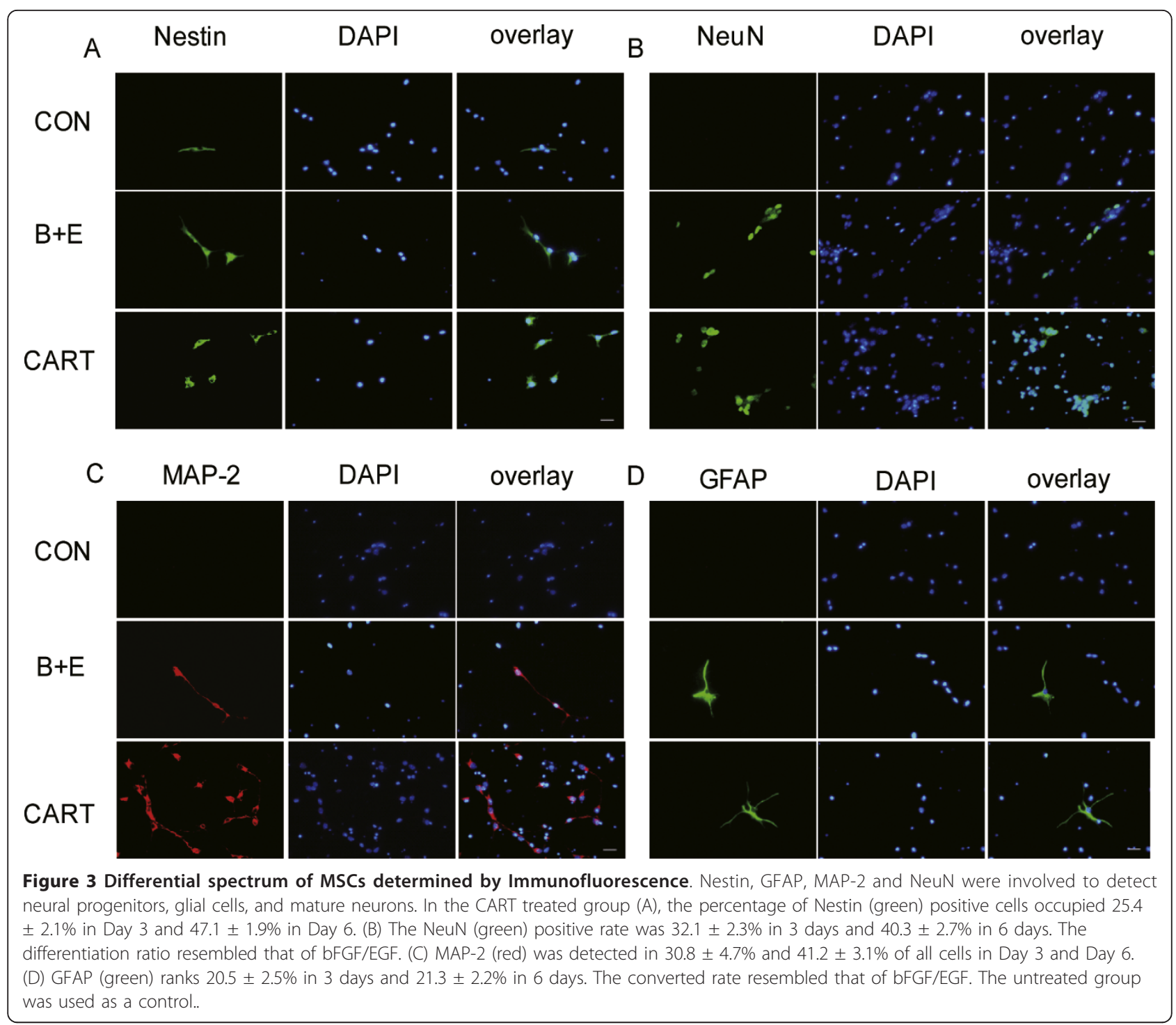

endogeneous expression of neurotrophic factors. Combined our previous studies [4,34], this study further confirmed the benefitial role of CART in the central nervous system. Besides the protective effect on neurons through complicated interaction with immunology and inflammation, CART also contributes to neuronal cells

Table 1 Differential spectrum of MSCs determined by Immunofluorescence

\begin{tabular}{cccccc}
\hline & & Nestin & MAP-2 & GFAP & NeuN \\
\hline 3d & CON & $8.2 \pm 2.2 \%$ & $2.7 \pm 0.8 \%$ & $1.4 \pm 0.3 \%$ & $3.1 \pm 1.2 \%$ \\
& CART & $25.4 \pm 2.1 \% *$ & $30.8 \pm 4.7 \%^{*}$ & $20.5 \pm 2.5 \%^{*}$ & $32.1 \pm 2.3 \%^{*}$ \\
& B+E & $27.1 \pm 2.0 \%$ & $29.3 \pm 3.7 \%$ & $11.4 \pm 2.6 \%$ & $31.1 \pm 2.9 \%$ \\
\hline $6 \mathrm{~d}$ & CON & $13.0 \pm 3.0 \%$ & $2.9 \pm 1.0 \%$ & $1.8 \pm 0.5 \%$ & $3.6 \pm 1.1 \%$ \\
& CART & $47.1 \pm 1.9 \%^{*}$ & $41.2 \pm 3.1 \% *$ & $21.3 \pm 2.2 \% \%^{*}$ & $40.3 \pm 2.7 \%^{*}$ \\
& B+E & $38.3 \pm 2.9 \%$ & $33.2 \pm 2.8 \%$ & $14.8 \pm 4.2 \%$ & $39.3 \pm 3.8 \%$ \\
\hline
\end{tabular}

$* \mathrm{p}<0.05$ versus control group differentiation and generation. In the future, CART pretreatment may become an attractive and implemental method in stem cell therapy for neurological disease.

\section{Methods}

Experimental animals and CART

Kunming mice (three-week old; $(20 \pm 2)$ g) were from the animal center of the Nanjing University of China. All mice were housed under a 12-hour light/dark cycle with food and water provided. The Animal Care and Use Committee of the Nanjing University approved all mouse protocols. CART was from Phoenix Pharmaceuticals, Inc. (USA).

\section{MSCs isolation, purification and culture}

Mice were killed by cervical dislocation, and bone marrow samples were collected from tibias and femurs for 


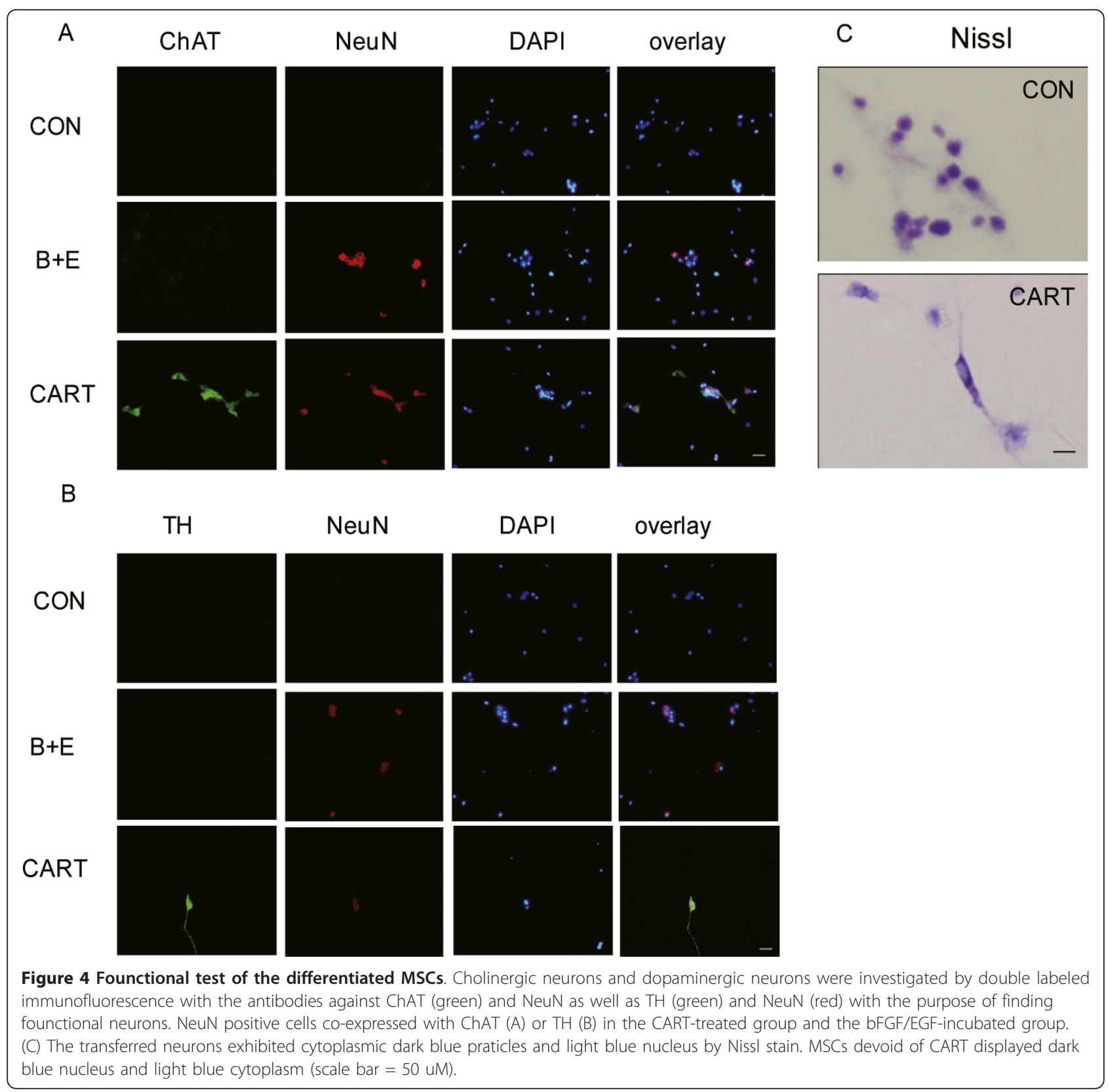

MSCs. MSCs were isolated according to the method described by Pittenger et al [1]. Mononuclear cells were resuspended in Dulbecco's Modified Eagle's Medium (DMEM, Gibco, USA), 20\% fetal bovine serum (FBS, Sigma, USA), $100 \mathrm{U} / \mathrm{ml}$ penicillin, and $100 \mu \mathrm{g} / \mathrm{ml}$ streptomycin. About $1 \times 10^{6}$ cells were plated into $25 \mathrm{~cm}^{2}$ flasks (Corning, USA) and incubated at $37^{\circ} \mathrm{C}$ with $5 \%$ $\mathrm{CO}_{2}$ and $95 \%$ relative humidity. The medium was first changed after 72 hours and then every 3 to 4 days thereafter. When the cultures reached approximately $90 \%$ of confluence, MSCs were recovered by the addition of $0.25 \%$ trypsin-ethylenediamine tetraacetic acid
(EDTA) solution (Invitrogen, USA) and replated into passage culture at 1:3. The purity of MSCs was over 95\% after 20 days from initial seeding.

\section{Characterization of isolated MSCs}

MSCs have the following characteristics: adherence to tissue culture plastic and several relatively specific cell surface markers [11]. The morphology of plastic adherent cells were monitored by an inverse microscope (TS100, Nikon, Japan). Cell surface molecules was analyzed on passage 3 cultures of MSCs using flowcytometry and the following procedures. Cells were detached 

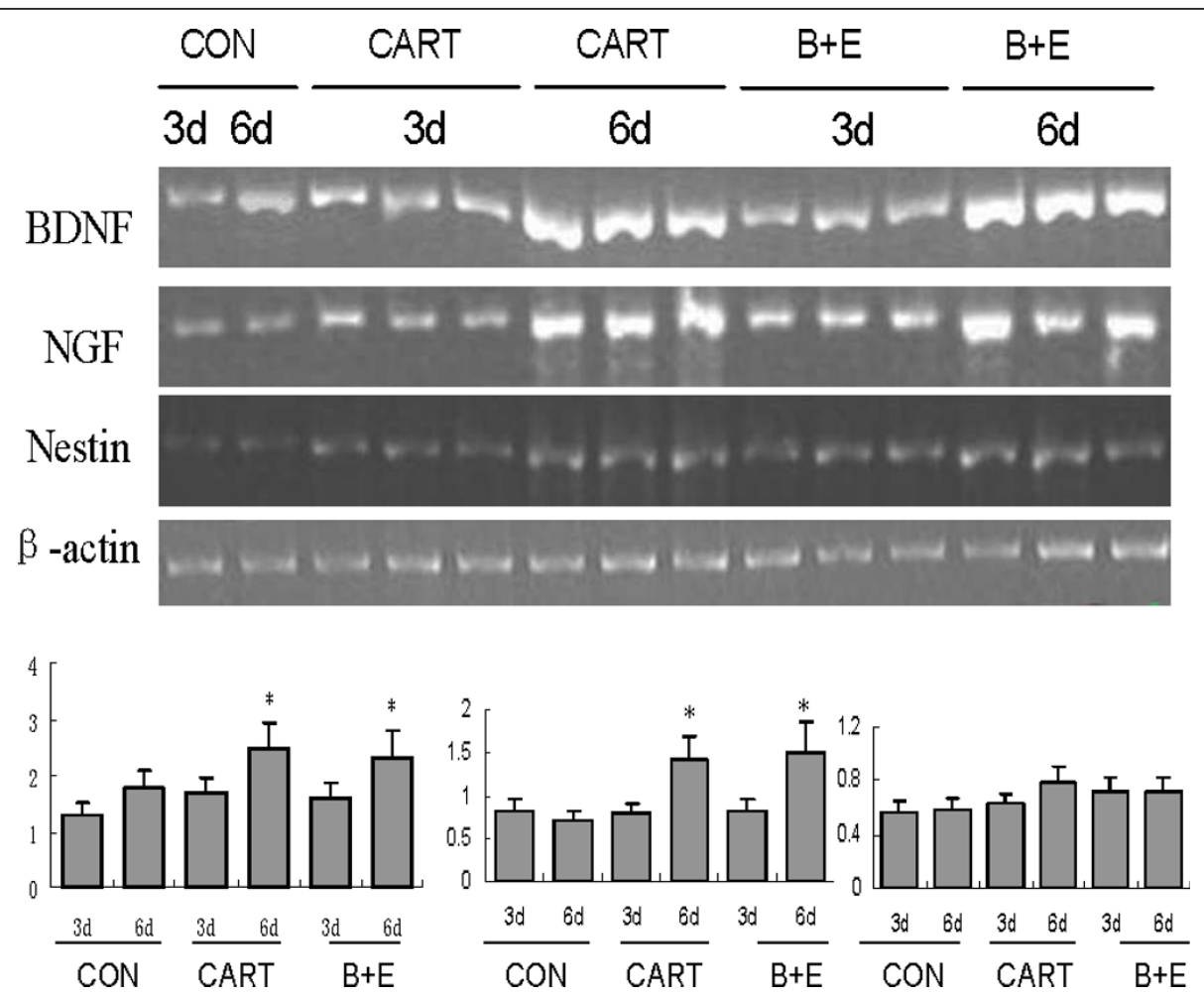

Figure 5 Neurotrophic factors effected by CART. RT-PCR was performed to calculate the endogenous expression of BDNF and NGF in Day 3 and Day 6. In contrast with the control group, the amount of BDNF was 1.68-fold and 2.45-fold higher with the incubation of CART at 3 days and 6 days. NGF was also higher with incubation of cart, with 1.05-fold of the control group in Day 3 and 2.01-fold of the control group in Day 6. There were no significant differences between CART treated-group and growth factor treated-group. ( ${ }^{*} p<0.05$ versus control group).

from the flask by incubation with a solution of $0.25 \%$ trypsin-EDTA for $5 \mathrm{~min}$ at room temperature. They were then recovered by centrifugation and washed in flowcytometry buffer consisting of $2 \%$ BSA and $0.1 \%$ sodium azide (Sigma) in PBS. They were separated into aliquots of $1 \times 10^{6}$ cells. Next, they were incubated with conjugated monoclonal antibodies, either CD34 and CD44 or CD29 and CD90 (Becton Dickinson, USA), for $20 \mathrm{~min}$. Washed cells were then incubated with secondary antibodies (Alexa-594 conjugated donkey anti-rabbit, 1:50 Jackson, USA) for $20 \mathrm{~min}$ in the dark. After washing, the cells were resuspended in 500 $\mu \mathrm{l}$ PBS and analyzed using a FACSCalibur software (Becton Dickinson, USA).

\section{Neuronal Induction}

Subconfluent passage 3 cultures of MSCs were maintained in DMEM $/ 20 \%$ FBS.

To initiate neuronal differentiation, the cells were washed with PBS and transferred to neuronal induction media composed of DMEM/0.4nM CART (Phoenix Pharmaceuticals, Inc.) at time ranging from 3 days to 6 days. As a positive control, MSCs were differentiated by DMEM/10 ug.ml ${ }^{-1}$ EGF/10 ug.ml ${ }^{-1}$ bFGF(Sigma, USA). At the end of the cultivation period, the cells were photographed and then fixed with frozen pyruvate for $10 \mathrm{~min}$, preparing for the immunofluorescence assay. The cells were also used for RNA extraction and reverse transcription-polymerase chain reaction (RT-PCR) analysis of neurogenic gene expression.

\section{Immunofluorescence Assay and Nissl stain}

MSCs were plated on the matrigel-coated dishes (FISHER, USA). The MSCs fixed by frozen pyruvate were permeabilited for $30 \mathrm{~min}$ in PBS containing 0.1\% Triton X-100. The samples were incubated with following primary antibodies at $4{ }^{\circ} \mathrm{C}$ overnight: antibodies for Nestin (1: 50, Sigma, USA), MAP-2 (1:100, Sigma, USA), GFAP (1:100, Sigma, USA), NeuN (1:100, Sigma, USA), ChAT (1:50, Sigma, USA), and TH(1: 100, Singma, USA). Primary antibodies were detected by using Cy2- or Cy3- conjugated goat anti-rabbit or antimouse secondary antibodies (1: 200, Sigma, USA) for 1 hour at room temperature. After reaction with secondary antibodies, the cells were stained with $100 \mathrm{nM}$ DAPI (Sigma, USA) for 15 seconds, then mounted. Fluorescence-labeled MSCs were viewed and photographed (AX10, ZEISS, German).

To detect Nissl bodies, differentiated cells were harvested and fixed in $4 \%$ neutral buffered formalin for $1 \mathrm{~h}$, and then stained for $30 \mathrm{~min}$ with $0.1 \%$ Cresyl violet in room tempreture. 


\section{Real-time quantitative PCR}

At 3 or 6 days, post-induction, the MSCs reached approximately $80 \%$ of confluence, and total RNA was extracted with Trizol (Invitrogen, USA) according to the manufacturer's instructions. cDNA was synthesized from RNA using the AMV reverse transcriptase (Gibco, USA). Real-time quantitative PCR was performed with a 7500 real-time PCR System (ABI 7500, USA). After initial denaturation, PCR was carried out for 30 cycles at $94^{\circ} \mathrm{C}$ for 45 seconds and $56^{\circ} \mathrm{C}$ for 45 seconds. Relative abundance of mRNA was calculated after normalization to GAPDH ribosomal RNA. The following primers were designed and used for real-time PCR:

BDNF: forward 5' ATG CTC AGC AGT CAA GTG CC 3', reverse 5' AGT AAG GGC CCG AAC ATA CG 3'

NGF: forward 5' AGC CCA CTG GAC TAA ACT TCA G 3', reverse 5' CAA AGG TGT GAG TCG TGG TGC A 3'

\section{Statistical Analysis}

Differences among treatment groups were analyzed with a t-test for two groups (SPSS 13.0, USA). The criterion for statistical significance was set at $P<0.05$. All values are reported as the mean \pm SEM.

\section{Additional material}

Additonal File 1: Excitable properties of MSC-derived neural like cells. (A) Voltage-gated potassium current was evoked by a series of depolarizing pulses from $-100 \mathrm{mV}$ to $+50 \mathrm{mV}$ stepping by $10 \mathrm{mV}$ with interval time of $5 \mathrm{sec}$. (B) voltage-gated calcium current was elicited by depolarizing to $-40 \mathrm{mV}$ (200 ms) from a holding potential of $-80 \mathrm{mV}$ and then further depolarized to $0 \mathrm{mV}(200 \mathrm{~ms}$ ) with interval time of $5 \mathrm{sec}$.

\section{List of abbreviations}

BM-MSC: bone marrow mesenchymal stromal cell; CART: cocaine- and amphetamine-regulated transcript; OGD: oxygen-glucose deprivation; BDNF: brain derived neurotrophic factor; NGF: nerve growth factor; bFGF: basic fibroblast grow factor; EGF: endothelial growth factor; ChAT:

cholineacetyltransferase; $\mathrm{TH}$ : tyrosine hydroxylase

\section{Acknowledgements}

This work was supported by the National Nature Science Foundation of China (30971010, 30670739), the Doctoral Program Foundation of the Ministry of Education of China (20060284044), the Outstanding Researcher Program (RC2007006), the National Nature Science Foundation (BK2009037) of Jiangsu Province of China, the 973 funding from the Ministry of Science and Technology in China (2009CB21906), funding from the State Key Laboratory of Pharmaceutical Biotechnology of Nanjing University (KF-GN200901). Postgraduate Innovation Project of Jiangsu Province (CX10B_027Z) and the Research Fund of Affiliated Drum Tower Hospital of Nanjing University Medical School for Youths.

\section{Author details}

'Department of Neurology, Drum Tower Hospital of Nanjing Medical University, 321 Zhongshan Road, Nanjing, Jiangsu, 210008, PR. China. ${ }^{2}$ Department of Neurology, Affiliated Drum Tower Hospital of Nanjing University Medical School, 321 Zhongshan Road, Nanjing, Jiangsu, 21008, PR. China. ${ }^{3}$ Department of Neurology, Jiangsu Province Geriatric Hospital, 65 Jiangsu Road, Nanjing, Jiangsu, 210024, PR. China. ${ }^{4}$ The State Key Laboratory of Pharmaceutical Biotechnology, Nanjing University, 22 Hankou Road,
Nanjing, Jiangsu, 210093, PR. China. ${ }^{5}$ Jiangsu Key Laboratory for Molecular Medicine, Nanjing University, 22 Hankou Road, Nanjing, Jiangsu, 210093, PR China. ${ }^{6}$ Department of Physiology, Nanjing Medical University, 140 Hanzhong Road, Nanjing, Jiangsu, 210029, PR China.

\section{Authors' contributions}

YX designed the experiments and edited this paper. ZL, DQH, LC carried out the experiments. ZBC did data analysis and made figures. MJZ and SYH helped to write the paper. ZZ and ZYW participated in part of the experiments. All authors read and approved the final manuscript.

Received: 10 January 2011 Accepted: 14 July 2011

Published: 14 July 2011

\section{References}

1. Pittenger MF, Mackay AM, Beck SC, Jaiswal RK, Douglas R, Mosca JD, Moorman MA, Simonetti DW, Craig S, Marshak DR: Multilineage potential of adult human mesenchymal stem cells. Science 1999, 284(5411):143-147.

2. Wu B, Hu S, Yang M, Pan H, Zhu S: CART peptide promotes the survival of hippocampal neurons by upregulating brain-derived neurotrophic factor. Biochem Biophys Res Commun 2006, 347(3):656-661.

3. Freeman RS, Burch RL, Crowder RJ, Lomb DJ, Schoell MC, Straub JA, Xie L: NGF deprivation-induced gene expression: after ten years, where do we stand? Prog Brain Res 2004, 146:111-126.

4. Xu Y, Zhang W, Klaus J, Young J, Koerner I, Sheldahl LC, Hurn PD, MartinezMurillo F, Alkayed NJ: Role of cocaine- and amphetamine-regulated transcript in estradiol-mediated neuroprotection. Proc Natl Acad Sci USA 2006, 103(39):14489-14494.

5. Madduri S, Papaloizos M, Gander B: Synergistic effect of GDNF and NGF on axonal branching and elongation in vitro. Neurosci Res 2009, 65(1):88-97.

6. Acheson A, Conover JC, Fandl JP, DeChiara TM, Russell M, Thadani A, Squinto SP, Yancopoulos GD, Lindsay RM: A BDNF autocrine loop in adult sensory neurons prevents cell death. Nature 1995, 374(6521):450-453.

7. Huang EJ, Reichardt LF: Neurotrophins: roles in neuronal development and function. Annu Rev Neurosci 2001, 24:677-736.

8. Abouelfetouh A, Kondoh T, Ehara K, Kohmura E: Morphological differentiation of bone marrow stromal cells into neuron-like cells after co-culture with hippocampal slice. Brain Res 2004, 1029(1):114-119.

9. Kopen GC, Prockop DJ, Phinney DG: Marrow stromal cells migrate throughout forebrain and cerebellum, and they differentiate into astrocytes after injection into neonatal mouse brains. Proc Natl Acad Sci USA 1999, 96(19):10711-10716.

10. Reyes M, Lund T, Lenvik T, Aguiar D, Koodie L, Verfaillie CM: Purification and ex vivo expansion of postnatal human marrow mesodermal progenitor cells. Blood 2001, 98(9):2615-2625.

11. Dominici M, Le Blanc K, Mueller I, Slaper-Cortenbach I, Marini F, Krause D, Deans R, Keating A, Prockop D, Horwitz E: Minimal criteria for defining multipotent mesenchymal stromal cells. The International Society for Cellular Therapy position statement. Cytotherapy 2006, 8(4):315-317.

12. Jiang $Y$, Jahagirdar $B N$, Reinhardt RL, Schwartz RE, Keene CD, OrtizGonzalez XR, Reyes M, Lenvik T, Lund T, Blackstad M, et al: Pluripotency of mesenchymal stem cells derived from adult marrow. Nature 2002, 418(6893):41-49.

13. Krause DS: Plasticity of marrow-derived stem cells. Gene Ther 2002, 9(11):754-758.

14. Prockop DJ: Marrow stromal cells as stem cells for nonhematopoietic tissues. Science 1997, 276(5309):71-74.

15. Brazelton TR, Rossi FM, Keshet Gl, Blau HM: From marrow to brain: expression of neuronal phenotypes in adult mice. Science 2000, 290(5497):1775-1779.

16. Coutts M, Keirstead HS: Stem cells for the treatment of spinal cord injury. Exp Neurol 2008, 209(2):368-377.

17. Hermann A, Liebau S, Gastl R, Fickert S, Habisch HJ, Fiedler J, Schwarz J, Brenner R, Storch A: Comparative analysis of neuroectodermal differentiation capacity of human bone marrow stromal cells using various conversion protocols. J Neurosci Res 2006, 83(8):1502-1514.

18. Sanchez-Ramos J, Song S, Cardozo-Pelaez F, Hazzi C, Stedeford T, Willing A, Freeman TB, Saporta S, Janssen W, Patel N, et al: Adult bone marrow stromal cells differentiate into neural cells in vitro. Experimental Neurology 2000, 164(2):247-256. 
19. Black IB, Woodbury D: Adult rat and human bone marrow stromal stem cells differentiate into neurons. Blood Cells Mol Dis 2001, 27(3):632-636.

20. Wislet-Gendebien S, Wautier F, Leprince P, Rogister B: Astrocytic and neuronal fate of mesenchymal stem cells expressing nestin. Brain Res Bull 2005, 68(1-2):95-102.

21. Song S, Zhang H, Cuevas J, Sanchez-Ramos J: Comparison of neuron-like cells derived from bone marrow stem cells to those differentiated from adult brain neural stem cells. Stem Cells Dev 2007, 16(5):747-756.

22. Xu R, Jiang X, Guo Z, Chen J, Zou Y, Ke Y, Zhang S, Li Z, Cai Y, Du M, et al: Functional analysis of neuron-like cells differentiated from neural stem cells derived from bone marrow stroma cells in vitro. Cell Mol Neurobiol 2008, 28(4):545-558.

23. Wu B, Hu SD, Yang M, Pan H, Zhu SG: CART peptide promotes the survival of hippocampal neurons by upregulating brain-derived neurotrophic factor. Biochemical and Biophysical Research Communications 2006, 347(3):656-661.

24. Liu Y, Dulchavsky DS, Gao X, Kwon D, Chopp M, Dulchavsky S, Gautam SC: Wound repair by bone marrow stromal cells through growth factor production. J Surg Res 2006, 136(2):336-341.

25. Hyman C, Hofer M, Barde YA, Juhasz M, Yancopoulos GD, Squinto SP, Lindsay RM: BDNF is a neurotrophic factor for dopaminergic neurons of the substantia nigra. Nature 1991, 350(6315):230-232.

26. Crigler L, Robey RC, Asawachaicharn A, Gaupp D, Phinney DG: Human mesenchymal stem cell subpopulations express a variety of neuroregulatory molecules and promote neuronal cell survival and neuritogenesis. Experimental Neurology 2006, 198(1):54-64.

27. Rivera FJ, Sierralta WD, Minguell JJ, Aigner L: Adult hippocampus derived soluble factors induce a neuronal-like phenotype in mesenchymal stem cells. Neurosci Lett 2006, 406(1-2):49-54.

28. Sanchez-Ramos J, Song S, Cardozo-Pelaez F, Hazzi C, Stedeford T, Willing A, Freeman TB, Saporta S, Janssen W, Patel N, et al: Adult bone marrow stromal cells differentiate into neural cells in vitro. Exp Neurol 2000, 164(2):247-256.

29. Klein R: Role of neurotrophins in mouse neuronal development. FASEB 1994, 8(10):738-744.

30. Barbacid M: Neurotrophic Factors and Their Receptors. Curr Opin Cell Biol 1995, 7(2):148-155

31. Vicario-Abejon C, Johe KK, Hazel TG, Collazo D, McKay RD: Functions of basic fibroblast growth factor and neurotrophins in the differentiation of hippocampal neurons. Neuron 1995, 15(1):105-114.

32. Palmer TD, Takahashi J, Gage FH: The adult rat hippocampus contains primordial neural stem cells. Mol Cell Neurosci 1997, 8(6):389-404.

33. Shetty AK, Turner DA: In vitro survival and differentiation of neurons derived from epidermal growth factor-responsive postnatal hippocampal stem cells: inducing effects of brain-derived neurotrophic factor. J Neurobiol 1998, 35(4):395-425.

34. Sha D, Li L, Ye L, Liu R, Xu Y: Icariin inhibits neurotoxicity of beta-amyloid by upregulating cocaine-regulated and amphetamine-regulated transcripts. Neuroreport 2009.

doi:10.1186/1471-2202-12-67

Cite this article as: Liu et al:: Cocaine- and amphetamine-regulated transcript promotes the differentiation of mouse bone marrow-derived mesenchymal stem cells into neural cells. BMC Neuroscience 2011 12:67.

\section{Submit your next manuscript to BioMed Central and take full advantage of:}

- Convenient online submission

- Thorough peer review

- No space constraints or color figure charges

- Immediate publication on acceptance

- Inclusion in PubMed, CAS, Scopus and Google Scholar

- Research which is freely available for redistribution 